\title{
EL Habeas Corpus ante las decisiones del Congreso de la República
}

\section{The Habeas Corpus before the decisions of the Congress of the Republic}

\author{
José Luis Rodríguez Medina
}

\section{RESUMEN}

Una de las funciones que tiene nuestro Congreso de la República en su rol político son las labores jurisdiccionales en el ámbito punitivo contra determinadas personas que han participado en la vida política nacional las cuales han sido fuertemente cuestionadas; toda vez que dichas decisiones sancionatorias cargadas de discrecionalidad, han sido dejadas sin efectos mediante la presentación de Habeas Corpus dejando impune el actuar de dichos investigados.

Palabras clave: Parlamento de la Republica, Labores Jurisdiccionales, Comisión Investigadora, discrecional de las decisiones del congreso, proceso de Habeas Corpus.

\begin{abstract}
One of the functions of our Congress of the Republic in its political role are the jurisdictional labours in the punitive field against certain people who have participated in national political life, which have been strongly questioned; since these sanctioning decisions laden with discretion have been left without effects through the presentation of Habeas Corpus leaving unpunished the actions of those investigated.
\end{abstract}

Keywords: Parliament of the Republic, Jurisdictional Labours, Investigative Commission, Discretionary of the Decisions of the Congress, Habeas Corpus Process.

\footnotetext{
${ }^{1}$ Abogado, Máster en Derecho Constitucional y Gobernabilidad, Profesor Asistente de la Facultad de Derecho y Ciencias Políticas de la Universidad Nacional Toribio Rodríguez de Mendoza de Amazonas. Correo electrónico:
} 


\section{INTRODUCCIÓN}

Desde la apertura democrática al golpe de Estado de 1992 con el Congreso Constituyente Democrático a la actualidad el rol político de Congreso de la República en la ejecución de labores jurisdiccionales en el ámbito punitivo contra determinadas personas que han participado en la vida política nacional ha sido sumamente cuestionable.

En este sentido, casi todas las medidas que han sido generadas en el Congreso de la República que han ejecutado una medida punitiva han provocado la intervención del Poder Judicial en un contexto de supuesto conflicto de poderes, pero que de por medio nos permite analizar el presente artículo, por cuanto en la mayoría de casos se ha podido observar una discrecionalidad sumamente relativa en el ámbito político en cuanto a la acción del Congreso contra una determinada persona.

Así por ejemplo podemos citar casos en los cuales el Poder Judicial prácticamente ha modificado la acción punitiva del Congreso de la República en el ámbito de una imposición de sanción, que pudo haber sido: destitución en el cargo, inhabilitación y suspensión en el ejercicio del cargo.

Ejemplos tan notorios como también tan referenciales para el caso que nos avoca en el presente trabajo. Así podemos citar:

a) En el caso de inhabilitaciones para el ejercicio de la función pública, el caso de Martha Chávez es el más notorio por cuanto a la señora se le sancionó con tal medida y el Poder Judicial revocó dichas sanciones y permitió no sólo la reincorporación de la mencionada política al Congreso de la República como parlamentaria durante el período legislativo 2001-2006, e inclusive determinó que como dicha sanción había sido anulada se le debía compensar económicamente.

b) El caso del Congresista José Luna Gálvez inicialmente acusado de "topo" por el Congreso de la República que provocó que durante los períodos 2001 al 2006 y en el 2006 al 2011 esté inhabilitado y por acción de la Corte Suprema se determinó que toda sanción del Congreso de la República no podía evitar su incorporación al Congreso como Congresista.

c) En el caos de suspensión en el cargo se puede mencionar el caso más representativo porque finalmente se complementó con el fallecimiento del Congresista Javier Diez Canseco, quien inicialmente fue suspendido en el cargo por haber sido acusado por acreditarse una conducta - vinculada al tráfico de influencias y beneficio directo en la promulgación de una ley que modificaba el registro societario en las empresas para la administración de las acciones.

Javier Diez Canseco titular de acciones nominales de un valor mínimo de una reconocida empresa cervecera nacional propuso un proyecto de ley que llegó a una instancia previa a la aprobación en la cual se pretendía equiparar a todas las acciones como "iguales" sin importar el valor nominal.

El beneficio directo a favor del congresista permitía que el patrimonio registrado en las acciones inicialmente que tenía se incrementasen en un aproximado de $400 \%$ con lo cual el "beneficio" resultaba acreditado, pero la ley finalmente no fue aprobada.

En la Comisión de Ética del Congreso de la República ese comportamiento fue sancionado y el Pleno del Congreso finalmente lo suspensión por 120 días, período en el cual el Congresista falleció.

En el transcurso de la suspensión el Congresista presentó un Habeas Corpus y el Poder Judicial le reconoció el derecho a levantar la sanción impuesta por el Congreso de la República porque finalmente el "beneficio" no fue "materializado", razón por la cual no podía configurarse una falta de corte ético.

Como se podrá observar, sólo se han mencionado algunos casos en los cuales aparentemente se han registrado "acciones desproporcionales a las funciones del Congreso de la República" a pesar de que constitucionalmente ese órgano estatal sí tiene las facultades para imponer medidas punitivas conforme lo determina el artículo 99 y 100 de la propia Constitución Política de 1993.

Como consecuencia de este panorama, y tomando en evidencia que últimamente se han generado dos situaciones, igualmente de corte político, es que planteamos en la presente oportunidad el estudio de la vinculación del ejercicio del ciudadano de interponer un Habeas Corpus contra una acción del Congreso de la República.

A efectos gráficos detallamos que los casos coyunturales contemporáneos que nos permitirán justificar la línea del presente trabajo se debe a los casos de:

a) La nulidad de las acciones y sanciones recomendadas al Pleno del Congreso de la República por parte de la "Mega comisión" del 
Congreso de la República de la Legislatura 2011 al 2016 en contra de Alan García Pérez, principalmente por las acusaciones de los "faenones", los "petro audios", las "licitaciones para la rehabilitación de los Colegios Emblemáticos" y otros casos de corrupción manifiesta durante el segundo gobierno aprista.

b) El caso de la instalación de la Comisión de investigaciones de la presunta injerencia política en el Ejecutivo por parte de Nadine Heredia, ex primera dama de la Nación, recientemente de "viaje de trabajo" a Suiza.

Ante estos hechos que son de notorio conocimiento, que nos permite presentar un tema teórico, debemos señalar que existen una serie de posiciones tanto desde el punto de vista constitucional y también desde una perspectiva político-penal respecto de las atribuciones del Congreso de la República respecto de sus atribuciones y por ello, vamos a ejecutar el siguiente análisis.

\section{EL CONTEXTO PARLAMENTARIO}

A efectos de poder detallar el desarrollo de las atribuciones del Congreso de la República, nos limitaremos a la labor que ejecuta el "procedimiento parlamentario", por medio del cual el Pleno del Congreso de la República se pronuncia respecto de una acción determinada, la cual puede ser:

a) Promulgación de una Autógrafa, esto es un Proyecto de Ley que por medio de un Dictamen es aprobado por la máxima instancia parlamentaria y es derivada al Presidente de la República para su promulgación a la firma del mandatario.

b) Promulgación de Decretos Legislativos que son las normas por excelencia del Congreso de la República por cuanto depende de su sola atribución y puede ser desde autorizaciones para viajes al extranjero del Presidente de la República, el nombramiento de altas autoridades como el Defensor del Pueblo, los Magistrados del Tribunal Constitucional, los directivos del Banco Central de Reserva o la simple compra de bienes por parte del Presidente del Congreso de la República.

c) Aprobación de comisiones extraordinarias y especiales en mérito a un tema en particular.

En este contexto, el Congreso de la República desarrolla la principal labor conocida por la ciudadanía en sus fueros que es la de "elaborar leyes" y este mecanismo se ejecuta a través del procedimiento de dictaminación, el cual se desarrolla en las Comisiones Ordinarias, las cuales se crean en función a la especialidad en directa proporción a los Ministerios del Poder Ejecutivo, para así poder desarrollar paralelamente la labor de fiscalización política al Gobierno Nacional.

Sin embargo, debido a las atribuciones amplias del Congreso de la República, el Congreso de la República por intermedio del Pleno puede crear las siguientes comisiones:

i. Comisiones extraordinarias, las cuales tiene por especial consideración el dedicarse a una actividad en específico, la cual puede ser:

- Fiscalización de algunos actos o la investigación a determinados personajes políticos.

- Desarrollo de una actividad específica en mérito a una ocasión especial, por ejemplo, se puede mencionar la Comisión extraordinaria de Personas con Discapacidad la cual históricamente ha sido presidida por el Congresista Javier Diez Canseco.

Igualmente se puede citar las Comisiones extraordinarias que ejecutan el procedimiento de reforma de normas especiales, por ejemplo en el actual periodo legislativo se han instalado las Comisiones extraordinarias de Reforma del Código Civil, Código Procesal Civil, Código Penal, Código Procesal Penal y Código Procesal Constitucional, en forma paralela a las Comisiones de Estudio de tales normas que desarrolla el Poder Ejecutivo a través del Ministerio de Justicia.

ii. Comisión Especial, la cual se crea principalmente cuando los temas de análisis a los cuales se avocará la comisión resultan complejos o requieren de un período de tiempo de trabajo superior a los seis meses.

La práctica parlamentaria es la que determina la variabilidad de las denominaciones en mérito principalmente a los objetivos a ser alcanzados en un período de tiempo determinado con anticipación.

De este modo, las Comisiones Extraordinarias sólo tienen un período de vigencia sumamente corto y no requieren de un mayor presupuesto por parte de la Mesa Directiva a favor de la instalación de estas comisiones.

En cambio las Comisiones Especiales sí requieren de un personal diferenciado del que conforma el 
Despacho Parlamentario y por ello se asigna un presupuesto especial y se aprueba un período superior de tiempo. Por ejemplo la "mega Comisión" del periodo legislativo del 2011 al 2016 prácticamente tuvo un período de duración de cinco años y finalmente no generó ninguna referencia de importancia tanto en lo político como en lo punitivo, porque todas sus decisiones, transitorias y de carácter punitivo, fueron anuladas por el Poder Judicial.

Frente a este panorama, analizaremos los siguientes aspectos:

\section{LAS ACCIONES POLÍTICAS EN LAS D I F E R E N T E S C O M I S I O N E S PARLAMENTARIAS}

Como es de natural evidencia, el Congreso de la República emite y ejecuta acciones de naturaleza política y resulta inevitable considerar que estas acciones políticas responderán principalmente al clima político que se desarrolle en un momento determinado y este no necesariamente puede provocar una acción previsible por parte de la ciudadanía.

Así por ejemplo, resulta cuestionable que el Congreso de la República cuando se trata de la evaluación de un acto cuestionable en lo ético o en une avaluación criminal en el ámbito penal no tenga acciones firmes contra el acusado si este forma parte del Congreso de la República como Congresista.

Salvo la destitución en el cargo de casos especiales, los cuales son minoría, en cada año legislativo se acusan a determinados Congresistas con acciones delictivas e inclusive con acciones de naturaleza ética que cuestionan su propia legitimidad frente al Congreso de la República.

Así por ejemplo, resulta cuestionable que por ejemplo no se hayan impuesto sanciones mucho más drásticas contra estos ex Congresistas, conforme a una explicación de la Comisión en la que participaron y los actos denunciados:

\section{a. COMISIÓN DE EDUCACIÓN, JUVENTUD Y DEPORTE}

a.1. Richard Acuña Núñez. La Libertad Profesión: Licenciado en Administración Cargo: fue miembro titular de la Comisión de Educación, Juventud y Deporte.

Actividad privada: Junto a su familia, es uno de los propietarios de las universidades César Vallejo, Señor de Sipán y Autónoma del Perú.
Actualmente este Congresista reelecto es el principal acto político en contra de las acciones de la SUNEDU, debido a que tiene intereses directos en la materia. A la fecha nunca se le ha denunciado por "beneficio directo en la promulgación de normas sobre la materia”.

\section{a.2. José Luis Elías Ávalos. Ica}

Profesión: Abogado

Cargo: fue miembro titular de la Comisión de Educación, Juventud y Deporte. Actividad privada: Fundador y director ejecutivo de la Universidad Privada San Juan Bautista desde abril del 2002. Este centro de estudios tiene un juicio por la propiedad de sus terrenos.

\section{b.COMISIÓN DE TRANSPORTE Y COMUNICACIONES}

\section{b.1. Esther Capuñay Quispe. Lima}

Profesión: Estudios de Economía. Cargo: Miembro titular de la Comisión de Transportes y Comunicaciones. Actividad privada: Es dueña, junto a su familia, de 64 radioemisoras agrupadas en la Corporación Universal S.A.C. Su padre tiene una denuncia por la presunta compra irregular de una radio.

\section{c. COMISIÓN DE SALUD Y POBLACIÓN}

\section{c.1. César Yrupailla Montes. San Martín Profesión: Médico cirujano.}

Cargo: Fue Vicepresidente de la Comisión de $\mathrm{S}$ a l u d $\quad \mathrm{y} \quad \mathrm{P}$ o b l a c i ó $\mathrm{n}$. Actividad privada: Propietario de la clínica privada San Marcos que pertenece a la Corporación Sefijo S.A.C., en Tarapoto (San Martín). Hasta enero ejerció el cargo de director médico. También es dueño de Ladrillos Tangarana E.I.R.L.

\section{c.2. Enrique Wong Pujada. Callao}

Profesión: Médico.

Cargo: Fue Secretario de la Comisión de Salud y Población.

Actividad privada: Es uno de los propietarios de la clínica privada San Vicente S.A. Ha sido denunciado por sus propios socios por el presunto delito contra el patrimonio en la modalidad de fraude en agravio de su empresa.

\section{d. COMISIÓN AGRARIA}

d. 1. Héctor Becerril. Amazonas- Lambayeque Profesión: Egresado de Farmacia y Bioquímica. Cargo: fue Miembro titular de la Comisión Agraria.

Actividad privada: Ha sido representante legal del complejo agroindustrial Tumán. Es hermano 
de Víctor Becerril, ex parlamentario y ex gerente general de Pomalca (perteneciente al Grupo Oviedo). Hasta el año 2016, el congresista Becerril fue el jefe de Control Patrimonial y Desarrollo Social de la Empresa Agroindustrial Pomalca S.A., en Chiclayo. En su declaración ante el JNE informó que estuvo en el cargo hasta enero del año 2016.

\section{e. COMISIÓN DE ENERGIA Y MINAS}

e.1. Néstor Valqui Matos. Cerro de Pasco

Profesión: Ingeniero metalúrgico.

Cargo: Fue Secretario de la Comisión de Energía y Minas

Actividad privada: Dueño de Secaval H\&N

S.A.C., empresa proveedora de diversos servicios a las mineras (construcción civil, metalurgia, alquiler de vehículos, asesoría técnica y ejecución de proyectos). Hasta enero de este 2016 fue presidente del directorio de esta empresa y también gerente de operaciones de Secominc S.R.L., compañía del mismo rubro. Hace cinco años, el Segundo Juzgado Especializado Penal de Pasco lo sentenció a dos años de cárcel por proxenetismo (trata de personas).

e.2. Eulogio Romero Rodríguez. Madre de Dios Profesión: Estudios inconclusos de Derecho Cargo: Fue miembro titular de la Comisión de Energía y Minas.

Actividad privada: Propietario de la Sociedad Minera de Responsabilidad Limitada Playa Nuevo Horizonte, en Madre de Dios, dedicada a la extracción de oro. Hasta enero de este año fue el gerente general de la empresa. Es el presidente del movimiento regional Mineros Unidos. La Sala Penal Liquidadora de Tambopata lo procesa desde hace seis años por el delito de peculado debido a la pérdida de un lote de madera del Inrena.

\section{f. C O M I S I Ó N D E V I V I E N D A Y CONSTRUCCIÓN}

f.1. Virgilio Acuña Peralta. Lambayeque

Profesión: Ingeniero civil.

Cargo: Fue miembro titular de la Comisión de Vivienda y Construcción

Actividad privada: Accionista de las constructoras Acuña y Peralta S.A. y Acuña y Peralta Negocios Inmobiliarios. El Estado ha sido uno de los clientes de sus empresas en los últimos 20 años, pero varias de sus adjudicaciones han sido cuestionadas. El 2007, Sedalib (empresa de agua de La Libertad) le entregó obras por S/.44 mlls., pese a que su empresa estaba impedida de participar porque su hermano César Acuña presidía la junta general de accionistas de Sedalib. El contrato se anuló.

Como se podrá observar, existen casos en los cuales sí puede acreditar un comportamiento al menos "anti ético" contra la función desempeñada pero el Congreso de la República no ha emitido ninguna sanción ni a nivel administrativo ni a nivel punitivo en el orden constitucional.

Caso muy diferente fue la situación de:

a. Elsa Canchaya (Unidad Nacional), desaforada por contratar a una empleada doméstica como asesora parlamentaria.

Lo paradójico de este caso fue el hecho de que una abogada que desempeñaba funciones de notaria, no sepa la diferenciación de funciones de ambas labores, una profesional y la otra de asistencia en el hogar.

Paradójico y emblemático fue el hecho de que la Corte Suprema falle a favor de la prescripción del "delito político" a favor de Elsa Canchaya y no se haya dispuesto el cumplimiento de la medida de destitución en forma efectiva porque la ex parlamentaria solicitó la indemnización que correspondía a un desafuero que finalmente no fue ratificado por el Poder Judicial.

b. Tula Benites (Apra), procesada en el Poder Judicial por la contratación de un empleado "fantasma". Empleado que cobraba puntualmente pero que por residir en provincias jamás se acercó al Cercado de Lima, donde funciona el Congreso de la República.

En este caso, la ex Congresista apeló a la Corte Suprema para invalidar la sanción impuesta y logró acceder al beneficio de la prescripción en la ejecución de un delito: atentar contra la libertad laboral de un empleado.

c. Gustavo Espinoza (Nacionalista), desaforado por filtrar información de "Estado" a parlamentarios chilenos. Si bien este es sólo un caso casi de farándula, Gustavo Espinoza debió ser desaforado por otras causas existentes previas a la filtración de un video contra Edwin Donayre, Comandante General del Ejército en ese momento.

d. Rocío Gonzales, conocida como la "roba luz", quien fuese sentenciada por no abonar los servicios de suministro eléctrico de la Compañía de Luz de Arequipa, con el agravante de que dicho suministro era ilegal, por eso el apelativo. 
e. Víctor Miro Ruiz, más conocido como el "mataperro", quien enfundara su escopeta para disparar contra un feroz perro, porque mataba a sus aves de corral.

Los hechos señalan que en realidad descargó su escopeta contra un cachorro shauzer, que no sobrepasa los 35 centímetros de alto y no se registró víctima alguna en sus corrales.

f. Álvaro Gutiérrez Cueva, quien fuese denunciado por su propia bancada parlamentaria, por gestionar viajes al exterior del país con financiamiento de entes cooperantes y trasladar dicho pago finalmente al mismo Congreso de la República.

En otras palabras, se gestionaban dobles viáticos, licencias fuera de plazos solicitados y toda una serie de situaciones complementarias.

Como se podrá observar, existen una serie de elementos que nos permiten señalar que la "acción política" del Congreso de la República es sumamente discrecional y depende de la persona en evaluación para que se ejecute una medida de orden punitivo, motivo que nos permite presentar ahora sí en forma teórica los principales aspectos del tema en evaluación.

\section{E L E L E V A D O C O N T E N I D O DISCRECIONAL DE LAS DECISIONES DEL CONGRESO}

En la evaluación teórico constitucional y penal sobre las facultades punitivas del Congreso de la República, podemos señalar que los artículos 99 y 100 de la Constitución Política nos permiten desarrollar el rol jurisdiccional en lo constitucional y político que desarrolla el "primer poder del Estado" en nuestro país.

Facultad que si bien es cierto está detallada en el ámbito constitucional y forma parte de las facultades históricas del Congreso, no necesariamente garantiza los siguientes principios:

a) El desarrollo de un debido proceso. Las facultades discrecionales del Congreso de la República en múltiples situaciones nos permite apreciar un proceso seguido de un secretismo sumamente peligroso frente a la eventual acción que desarrollarán que limita en esencia los derechos fundamentales del ciudadano en evaluación.

b)El acceso a una Tutela Jurisdicción en lo constitucional efectiva, debido sobre todo a que los derechos de la parte acusada no son garantizados sino hasta el momento en que se determina la medida político constitucional final.

c) El principio de inocencia.

Situación que nos permite observar que aún inclusive con una decisión jurisdiccional del Poder Judicial el Congreso de la República puede mantener una decisión de corte político respecto de una inhabilitación o suspensión política, porque estas facultades son discrecionales y no garantizan una relación y proporcionalidad con la inocencia detallada en una decisión judicial.

d) El deber de motivar una decisión.

Situación que parte por la facultad discrecional del Congreso de la República respecto de situaciones políticas que a criterio de la mayoría parlamentaria no puede ser predictible porque se ha observado casos similares que han generado situaciones muy diferenciadas.

\section{EL ÁMBITO DE LA REGULACIÓN DE LAS SANCIONES QUE PUEDE IMPONER EL CONGRESO DE LA REPÚBLICA}

Como se ha detallado inicialmente, el Congreso de la República puede ejecutar la imposición de las siguientes sanciones de carácter penal

a) Medida de llamada de atención.

Esta acción es sólo una medida de corte provisional y usualmente se da en el ejercicio de la participación política en el debate político que ejecuta un Congresista.

b) Medida de suspensión en el ejercicio del cargo. Medida que en los últimos cinco años ha sido desarrollada a propuesta de la Comisión de Ética del Congreso de la República y trata de casos y situaciones en las cuales el Congresista ha ejecutado una acción indebida o que contradice los objetivos del Congreso.

c) Medida de destitución en el ejercicio de la función pública.

En este contexto, la destitución se considera una sanción penal en forma específica por cuanto involucra una limitación a los derechos de una persona que se ha generado en mérito al desarrollo de un procedimiento que en este caso no garantiza los principios de orden constitucional y procesal.

d) Medida de inhabilitación en el ejercicio de la función pública. 
Medida punitiva más grave en el orden constitucional y que ha sido considerada sólo en casos extremos.

La última persona en ser inhabilitada para la función pública ha sido Alberto Fujimori Fujimori.

\section{LAS ACCIONES CONSTITUCIONALES CONTRA LAS DECISIONES DEL CONGRESO DE LA REPÚBLICA}

Conforme a lo detallado en los puntos precedentes, como se puede observar las decisiones del Congreso de la República son sumamente discrecionales en cuanto se trata de decisiones de carácter jurisdiccional en el ámbito punitivo y ello puede provocar la consecuente indefensión de una persona, investigada, acusada o sancionada por el primer poder del Estado.

Ante este tipo de situaciones es que ha sido usual en la práctica política peruana la interposición de medidas cautelares y solicitudes de habeas corpus contra el propio Congreso, conforme se puede detallar:

a) Habeas Corpus de Alejandro Toledo contra el Congreso de la República.

Si bien esta medida fue finalmente declarada infundada por el propio Tribunal Constitucional, se debe señalar que mientras duró el trámite judicial el Congreso de la República, a través de la Comisión de Fiscalización y la propia Fiscalía de Lavado de Activos que sigue un proceso ordinario por enriquecimiento indebido contra el ex Presidente no pudieron ejecutar acciones de naturaleza política (por ejemplo imponer una inhabilitación en el ejercicio de la función pública) o de naturaleza jurisdiccional: un embargo preventivo sobre los bienes del ex Presidente.

Todas estas acciones se generaron por la compra de bienes y el registro como titular registral de la señora suegra del ex Presidente, decretándose preliminarmente que la operación financiera no cuadraba con los balances económicos de la mencionada titular registral.

b) Las acciones constitucionales de la señora Nadine Heredia contra el Congreso de la República.

Durante el año 2016 a raíz de las investigaciones que ejecuta el Congreso de la Legislatura 20162021 se han instalado comisiones especiales que tienen por objetivo ejecutar la constatación de la intromisión política de la ex primera dama en la dirección del Gobierno Nacional.
Como consecuencia de estos actos del Congreso, Nadine Heredia ha ejecutado la interposición de Habeas Corpus y Acciones de Amparo contra varias decisiones parlamentarias, todos los cuales han sido declarados infundados porque la pretensión inicial procuraba diferenciar la figura de la "primera dama" de la "intervención política sobre el Presidente de la República", generando la imagen de que la primera dama no podría haber intervenido en las decisiones del Presidente de la República.

Por estos argumentos es que el Poder Judicial no ha concedido ningún Habeas Corpus y Amparo a favor de Nadine Heredia, por cuanto el argumento principal de los diferentes jueces ha sido el mismo: es facultad del Congreso de la República ha investigar a todo ciudadano peruano sin mediar justificación.

A raíz de las investigaciones de Lavado de Activos contra la ex primera dama, las nuevas medidas constitucionales interpuestas igualmente fueron decretadas como infundadas.

c) Los Habeas Corpus de Alan García contra el Congreso.

A raíz de la investigación ejecutada por la Mega Comisión presidida por el ex Congresista, Sergio Tejada, contra los actos de corrupción del II Gobierno Aprista, el ex Presidente interpuso una serie de acciones de corte ordinario (Medidas Cautelares), Habeas Corpus y Acciones de Amparo para tutelar sus supuestos derechos vulnerados: presunción de inocencia, imposibilidad de acceder a un debido proceso en el ámbito parlamentario e inaccesibilidad a una tutela jurisdiccional político constitucional debido.

Eventualmente las medidas han llegado hasta el propio Tribunal Constitucional por las apelaciones formuladas tanto por el Congreso de la República como también por la Procuraduría Pública de la Nación, quien investigaba también actos de corrupción contra ese gobierno.

Finalmente toda las acciones fueron decretadas como fundadas tanto por el Poder Judicial como por el Tribunal Constitucional, debido principalmente a que los procedimientos ejecutados por el Congreso de la República, no garantizaban ni la inocencia del acusado, ni el debido procedimiento, ni otros principios de orden constitucional y procesal.

Ante el panorama descrito nos centraremos en el 
análisis del Habeas Corpus, por cuanto nos permite delimitar de mejor manera nuestra posición en el presente trabajo.

\section{EL HABEAS CORPUS: PAUTAS TEÓRICAS}

Como referencia histórica, el Habeas Corpus es una institución que aparece en la Inglaterra del siglo XII, pero que registra antecedentes en la época del Imperio Romano y en los fundamentos filosóficos de la cultura Griega.

Finalmente, para lo que corresponde en su estudio dogmático, se debe señalar que el Habeas Corpus es una medida que procede en la defensa de la libertad como parte del conjunto de derechos y garantías individuales que tiene toda persona, dado el carácter fundamental y de derechos humanos que le asiste.

Por su importancia, nos limitaremos a describir algunas características esenciales del Habeas Corpus:

a)Es un proceso sumario, por cuanto en un procedimiento expedito un juez puede resolver una controversia en forma "inmediata".

b)Es un proceso subsidiario, por cuanto no se requiere de la ejecución de otras acciones procesales y por medio de este proceso se define la libertad de una persona.

c)Es informal, justamente a razón de su naturaleza sumaria y subsidiaria.

Como consecuencia de estas características surgen tipos de Habeas Corpus, como:

a)Habeas Corpus reparador, las cuales se dirigen contra detenciones calificadas como arbitrarias.

Téngase en cuenta que, en nuestro tema de estudio, la mayoría de decisiones sobre Habeas Corpus contra las acciones del Congreso podrían determinarse bajo esta naturaleza, pero en buena medida el Congreso nunca ha generado ninguna situación de "orden de comparecencia bajo mandato de detención" a pesar de tener la facultad para ello.

b)Habeas Corpus restringido, el cual procede cuando se trata de limitar actos restrictivos que sin implicar detención afectan la libertad de manera continua, pues la misma se está restringiendo en los hechos.

c)Habeas Corpus correctivo, el cual pretende suprimir las condiciones de maltrato o mejorar la situación de aquella persona cuya libertad está ya restringida.

d)Habeas Corpus preventivo, el cual se postula cuando existe una amenaza contra la libertad individual.

e)Habeas Corpus traslativo, el cual procede cuando el proceso judicial ordinario se demora y viola el principio de celeridad, inocencia y debido proceso.

f)Habeas Corpus innovativo, el cual procede la tutela de un derecho que ya ha sido afectado.

g)Habeas Corpus instructivo, cuando se genera una situación de violación de la libertad en forma complementaria con la acción de un agente del Estado que restringe su comunicación o ubicación respecto de sus familiares, con lo cual su defensa se limita.

Ante este tipo de situaciones, el Habeas Corpus en esencia pretende la defensa de la libertad y ello usualmente es materia de evaluación en el Congreso de la República por cuanto en los últimos años este primer poder del Estado a remitido al Ministerio Público acusaciones de corte constitucional acompañado con pedidos expresos de inicio de formalización de una acusación penal de corte constitucional por la acreditación de "supuestos delitos".

\section{LA DEFENSA DE LA LIBERTAD POR PARTE DE UN SUJETO ACUSADO POR EL CONGRESO DE LA REPÚBLICA}

Sobre la base de los datos referenciales antes enunciados, como se podrá observar, la mayoría de los investigados por el Congreso de la República ha tenido procesos judiciales de naturaleza penal y ante el peligro potencial que conlleva el desarrollo de un procedimiento parlamentario de acusación constitucional que puede provocar una inhabilitación en el ejercicio de un cargo público, la mayoría de acusados e investigados por el Congreso de la República ha ejecutado acciones constitucionales contra dicha entidad, planteando principalmente Habeas Corpus por cuanto la libertad de los mismos para actuar en su propia defensa han sido restringidos.

\section{CONCLUSIÓN}

Finalmente y como consecuencia de lo expuesto, tomando en cuenta lo referencial y coyuntural de la situación político constitucional de muchos de los investigados por el Congreso de la República, podemos señalar como elementos conclusivos, los siguientes puntos: 
a)El Congreso de la República tiene facultades jurisdiccionales de naturaleza penal, por cuanto puede investigar y puede imponer medidas punitivas que van desde la llamada de atención hasta la inhabilitación en el ejercicio de un cargo público.

b)El Congreso de la República si bien puede ejecutar acciones jurisdiccionales, debe garantizar el debido proceso y la tutela judicial efectiva y como se ha detallado, la mayoría de situaciones no cumple con estos parámetros y por ello, el Poder Judicial corrige las decisiones del Congreso de la República.

c)Que este "aparente conflicto" de poderes, en esencia no existe por cuanto ni el Poder Judicial limita las facultades del Congreso de la República, ni las acciones del Congreso afectan la naturaleza jurisdiccional por cuanto su naturaleza es política y ante la elevada discrecionalidad que puede variar en el tiempo, el Congreso puede imponer una medida sancionatoria sin generar una afectación a los derechos fundamentales de una persona.

\section{REFERENCIAS BIBLIOGRÁFICAS}

ASAMBLEA LEGISLATIVA DE COSTA RICA. (2005). Revista Parlamentaria. San José de Costa Rica, Volumen 13

Berlín, F. (1993). Derecho parlamentario. México, Fondo de Cultura Económica. P. 23.

Brewer, A. (2009). Constitutional protection of human rights in Latin America. Cambridge, Cambridge University.

EL COMERCIO. (2016). TC declaró infundado el Habeas Corpus de Alejandro Toledo. Recuperado el 20/11/2016 En: http://elcomercio.pe/politica/justicia/tcdeclara-infundado-habeas-corpus-toledocontra-congreso-noticia-1853612

Ferrero, Raúl. (2001). Perú, secuestro y rescate de la democracia. México, Fondo de Cultura Económica.

García, F. (2015). Tipos de habeas corpus en la jurisprudencia del Tribunal Constitucional. Lima, Gaceta Jurídica. P. 24.

LAMULA.PE. (2016). Poder Judicial anula de forma definitiva denuncias de "megacomisión" contra Alan García. Recuperado el 22/11/2016 en: https://redaccion.lamula.pe/2015/11/19/pode r-judicial-anula-de-forma-definitivadenuncias-de-megacomision-contra-alangarcia/rbautista/

Martínez, G. (1998). Fiscalización parlamentaria y comisiones investigadoras. Santiago de
Chile, Editorial Jurídica de Chile. P. 67.

Oehling de los Reyes, A. La dignidad de la persona. Madrid, Dykinson. P. 1207.

Plasencia, L. (2014). El habeas corpus contra actos de investigación preliminar. Lima, Gaceta Jurídica.

PERU 21. (2016). Nadine Heredia: ¿Qué es una acción de amparo y un hábeas corpus? Recuperado el 22/11/2016 En: http://peru21.pe/politica/nadine-heredia-queaccion-amparo-y-habeas-corpus-2226214

Santaolalla, F. (2013) Derecho parlamentario español. Madrid, Dykinson. P. 38

Vigo, H. (1989). El Habeas Corpus. Lima, Cultural Cuzco.

UNIVERSIDAD CATÓLICA SAN ANDRES. (2007). Debido proceso y medidas de coerción personal. Santiago de Chile, UCAB. p. 127. 